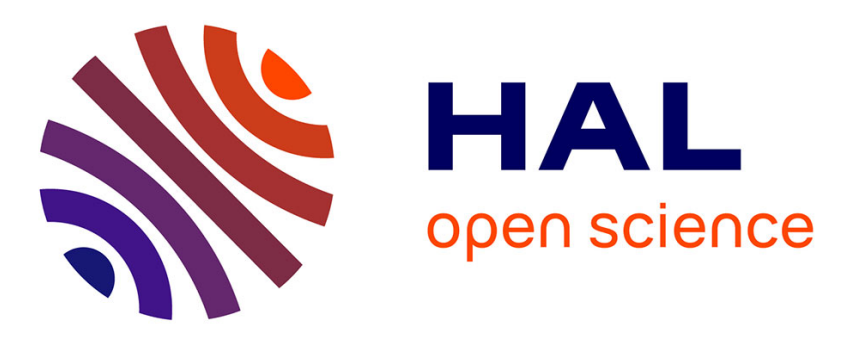

\title{
Mononuclear Lanthanide Complexes Containing [O-O]-Chelating Sulfonylamidophosphate Type Ligands
}

Angelina Prytula-Kurkunova, Céline Pichon, Carine Guyard-Duhayon, Vladimir Amirkhanov, Jean-Pascal Sutter

\section{- To cite this version:}

Angelina Prytula-Kurkunova, Céline Pichon, Carine Guyard-Duhayon, Vladimir Amirkhanov, JeanPascal Sutter. Mononuclear Lanthanide Complexes Containing [O-O]-Chelating Sulfonylamidophosphate Type Ligands. European Journal of Inorganic Chemistry, 2019, 2019 (42), pp.4592-4596. 10.1002/ejic.201900976 . hal-02367488

\section{HAL Id: hal-02367488 \\ https://hal.science/hal-02367488}

Submitted on 10 Nov 2020

HAL is a multi-disciplinary open access archive for the deposit and dissemination of scientific research documents, whether they are published or not. The documents may come from teaching and research institutions in France or abroad, or from public or private research centers.
L'archive ouverte pluridisciplinaire HAL, est destinée au dépôt et à la diffusion de documents scientifiques de niveau recherche, publiés ou non, émanant des établissements d'enseignement et de recherche français ou étrangers, des laboratoires publics ou privés. 


\title{
Mononuclear Lanthanide Complexes Containing [O-O]-Chelating Sulfonylamidophosphate Type Ligands
}

\author{
Angelina Y. Prytula-Kurkunova, ${ }^{\mathrm{a}, \mathrm{b}}$ Céline Pichon, ${ }^{\mathrm{b}}$ Carine Duhayon, ${ }^{\mathrm{b}}$ Vladimir M. Amirkhanov, ${ }^{\mathrm{a}}$ \\ Jean-Pascal Sutter ${ }^{* b}$ \\ ${ }^{a}$ National Taras Shevchenko University of Kyiv, Department of Chemistry, 12 Lva Tolstogo str., 01033 \\ Kyiv, Ukraine \\ ${ }^{b}$ LCC-CNRS, Université de Toulouse, CNRS, 31077 Toulouse, France. \\ * jean-pascal.sutter@1cc-toulouse.fr
}

\section{Academic titles}

Mrs A.Y. Prytula-Kurkunova; Dr. Céline Pichon; Dr. Carine Duhayon; Prof. Vladimir M. Amirkhanov; Dr. J.-P. Sutter

\begin{abstract}
The ability of a sulphonyl amidophosphate (SAPh) compounds having the structural fragment $\mathrm{RSO}_{2} \mathrm{NHP}(\mathrm{O}) \mathrm{R}_{2}$ to act as a $\beta$-diketone homologue for the complexation of $\operatorname{Ln}(\mathrm{III})$ ions has been explored. We report the synthesis and magnetic properties of five mononuclear complexes of formula $\mathrm{LnL}_{3}$ Phen (L stands for deprotonated bis(methyl(phenyl)amino)phosphoryl)benzene sulfonamide, $\mathrm{C}_{6} \mathrm{H}_{5} \mathrm{SO}_{2} \mathrm{NP}(\mathrm{O})\left[\mathrm{N}\left(\mathrm{CH}_{3}\right)\left(\mathrm{C}_{6} \mathrm{H}_{5}\right)\right]_{2}$, and Phen for

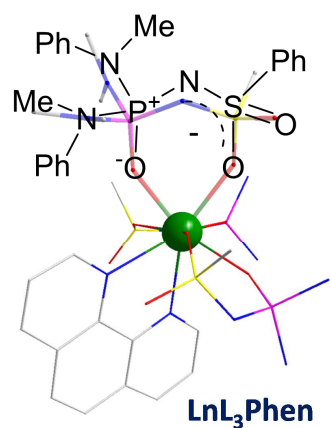
Ln $=\mathrm{Tb}^{\prime \prime \prime}, \mathrm{Dy} \mathrm{y}^{\mathrm{III}}, \mathrm{Ho}{ }^{\mathrm{III}}, \mathrm{Er}{ }^{\prime \prime \prime}, \mathrm{Yb} \mathrm{b}^{\prime \prime \prime}$ phenanthroline) with $\mathrm{Ln}=\mathrm{Tb}^{\mathrm{III}}$, $\mathrm{Dy}^{\mathrm{III}}, \mathrm{Ho}^{\mathrm{III}}, \mathrm{Er}^{\mathrm{III}}$, and $\mathrm{Yb}^{\mathrm{III}}$, along with the X-ray structure of the Dysprosium and Ytterbium compounds. In-field SMM behaviors were observed for the Dy and Er derivatives.
\end{abstract}

Key topic: Lanthanide complexes 


\section{INTRODUCTION}

In the field of molecular magnetism, Single-Molecule Magnets (SMMs) are a class of moleculebased magnets exhibiting slow relaxation of the magnetization and magnetic hysteresis akin to the bulk magnets. ${ }^{[1]}$ SMMs are appealing systems as their properties originate from individual molecules. The first observation of slow relaxation of the magnetization in mononuclear lanthanide complexes in $2003^{[2]}$ has emulated a flourishing research activity and record energy barriers and blocking temperatures as high as $2217 \mathrm{~K}$ and $80 \mathrm{~K}$ respectively, were recently reported for a dysprosium organometallic complex. ${ }^{[3]}$ Some robust SMMs have already been deposited on surfaces ${ }^{[4-5]}$ or incorporated in devices ${ }^{[6-7]}$ since potential applications in data storage or quantum computing have been proposed. ${ }^{[8]}$

Lanthanide ions are well suited to achieve large energy barriers and blocking temperatures due to their strong spin-orbit coupling and magnetic moment. ${ }^{[9-12]}$ As a consequence, the orbital contribution to the magnetic moment is large and unquenched (except for ${ }^{1} \mathrm{~S}_{0}$ and ${ }^{8} \mathrm{~S}_{7 / 2}$ ground electronic terms) while the ligand field is acting as a weaker perturbation. Both effects are strongly dependent of the lanthanide coordination sphere's symmetry and modulate the local magnetic anisotropy and relaxation properties. Various coordination spheres (geometry and ligand field) were explored with coordination number ranging from 2 to 9 to study the effect of these parameters on the magnetic properties and to gather magneto-structural information. ${ }^{[13-14]}$ However, the great majority of systems are eight-coordinated lanthanide ions in square antiprism $^{[15-16]}$, bicapped triangular prism ${ }^{[17]}$ or dodecahedron ${ }^{[18]}$ geometry. Such complexes very often involve $\beta$-diketonate ligands. They comprise homoleptic ${ }^{[19-20]}$ or heteroleptic complexes with different auxiliary ligands around the lanthanide. ${ }^{[21-25]}$ Bipyridine is the most frequent auxiliary ligand combined with $\beta$-diketones Dy(III) mononuclear complexes ${ }^{[26-31]}$ followed by phenantroline. ${ }^{[26-29,32-33]}$ Notably, Chen et al. reported a significant modification of the energy barrier by substitution of two water molecules by a bipyridine ligand. ${ }^{[34]}$ Alternative to $\beta$ diketonate ligands have been much less considered but one may mention complexes with a bisphosphonate chelate ligand. ${ }^{[35]}$ 
It was shown that $\mathrm{SAPh}$ (sulphonylamidophosphate) type compounds can be considered as structural analogous of $\beta$-diketones and act as ligands ${ }^{[36]}$ for transition metal ions ${ }^{[37]}$ and for lanthanides ions. ${ }^{[38-39]}$ Herein, the structural fragment $\mathrm{RSO}_{2} \mathrm{NHP}(\mathrm{O}) \mathrm{R}_{2}$ of the deprotonated $\mathrm{SAPh}$ $\mathrm{N}$-(bis(methyl(phenyl)amino)phosphoryl)benzenesulfonamide (Scheme 1) was used as [O-O] chelate for the complexation of paramagnetic $\operatorname{Ln}(\mathrm{III})$ ions. The ability of this ligand to coordinate lanthanide ions was illustrated recently with $\mathrm{La}(\mathrm{III}) .{ }^{[40]}$ A series of neutral complexes of general formula $\left[\mathrm{LnL}_{3}\right.$ (phen) $] \cdot 0.5 \mathrm{H}_{2} \mathrm{O}$ with $\mathrm{L}=$ deprotonated $\mathrm{SAPh}$, phen $=1.10$-phenanthroline, and $\mathrm{Ln}$ = $\mathrm{Tb}$ (1), Dy (2), Ho (3), Er (4) and Yb (5) are reported. These metal ions have been considered with respect to possible SMM behavior that was indeed evidenced for the Dy and Er derivatives.

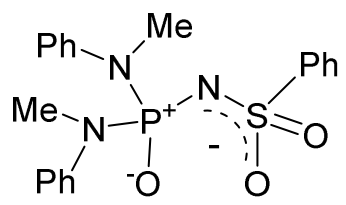

Scheme 1: Sketch of the anionic sulphonyl amidophosphate ligand

\section{RESULTS AND DISCUSSION.}

Syntheses. The lanthanide complexes $\left[\mathrm{LnL}_{3}(\right.$ phen $\left.)\right] \cdot 0.5 \mathrm{H}_{2} \mathrm{O}$, with $\mathrm{Ln}=\mathrm{Tb}(\mathbf{1}), \mathrm{Dy}(\mathbf{2}), \mathrm{Ho}(\mathbf{3}), \mathrm{Er}$ (4), and $\mathrm{Yb}(\mathbf{5})$, were obtained almost quantitatively by reaction of the corresponding hydrated $\mathrm{Ln}\left(\mathrm{NO}_{3}\right)_{3}$ salt with 3 equivalents of $\mathrm{NaL}$ and 1 equivalent of phenantroline in $\mathrm{MeOH}$. The neutral compounds 1-5 precipitated in solution and were crystallized from acetone solutions by $\mathrm{Et}_{2} \mathrm{O}$ diffusion. All the subsequent characterizations have all been performed on crystalline samples. Solid state infrared spectra of the complexes show the characteristic symmetric and asymmetric stretching bands of the $\mathrm{SO}_{2}$ group around 1125 and $1244 \mathrm{~cm}^{-1}$ respectively, while the band around $1165 \mathrm{~cm}^{-1}$ is the signature of the PO bond. These bands arise at lower energies compared to the related stretching in $\mathrm{HL}^{[40]}$ as a result of the coordination of the $\mathrm{SO}_{2}$ and $\mathrm{PO}$ groups to a $\mathrm{Ln}$ center.

The unit cell parameters ascertained for 1-5 (Table 1) show that the complexes are isostructural. This is confirmed by the crystal structures solved for the $\mathrm{Dy}$ and $\mathrm{Yb}$ derivatives. The structure of 
5 will be shortly commented as a representative. The limited quality of the data refinement for $\mathbf{2}$ does not allow commenting bond distances and angles but the same structural arrangement applies (Figure SI1).

Crystal structure. Compound $\mathbf{5}$ crystallized in the triclinic P-1 space group. Its structure consists in a discrete complex formed by a $\mathrm{Yb}(\mathrm{III})$ surrounded by three [O-O] chelating $\mathrm{L}^{-}$ligands and one bidentate phenanthroline, co-crystallized with half a $\mathrm{H}_{2} \mathrm{O}$ molecule (Figure 1). As a result the $\mathrm{Yb}^{\mathrm{III}}$ ion is eight-coordinated by two nitrogen atoms and six oxygen atoms. This molecular arrangement is reminiscent to that of the $\mathrm{La}$ (III) homologue which however, was found to crystallize in a different space group, likely due to different crystallization conditions. ${ }^{[40]}$ The $\mathrm{Yb}$ $\mathrm{O}(\mathrm{S})$ bonds are longer than the $\mathrm{Yb}-\mathrm{O}(\mathrm{P})$ ones with average values of 2.35 and $2.22 \AA$, respectively (see caption to Figure 1) which can be ascribed to the larger negative charge on the $\mathrm{O}$ of the phosphoryl group due to the strongly polarized $\mathrm{P}^{+}-\mathrm{O}^{-}$charge distribution. Despite the deprotonated bridging $\mathrm{N}$-atom, a related situation does not apply for the SO moiety most likely because the delocalization involves the two O-atoms of the $\mathrm{SO}_{2}$ group. This is supported by the very similar S-O bond lengths for the coordinated (1.472 $\AA$ ) and non-coordinated (1.441 $\mathrm{\AA}$ ) Oatoms. The evaluation of the polyhedral shapes of the Ln coordination spheres by Continuous Shape Measures ${ }^{[41-42]}$ performed with SHAPE ${ }^{[43]}$ indicates a geometry close to square antiprism (Table SI2). Regarding the crystal packing, the molecules are efficiently separated due to the bulky ligands. They are organized in pairs with a shortest intermetallic distance of $10.35 \AA$ due to intermolecular $\pi \cdots \pi$ interactions between the aromatic rings of the phenanthrolines (Figure SI2). 


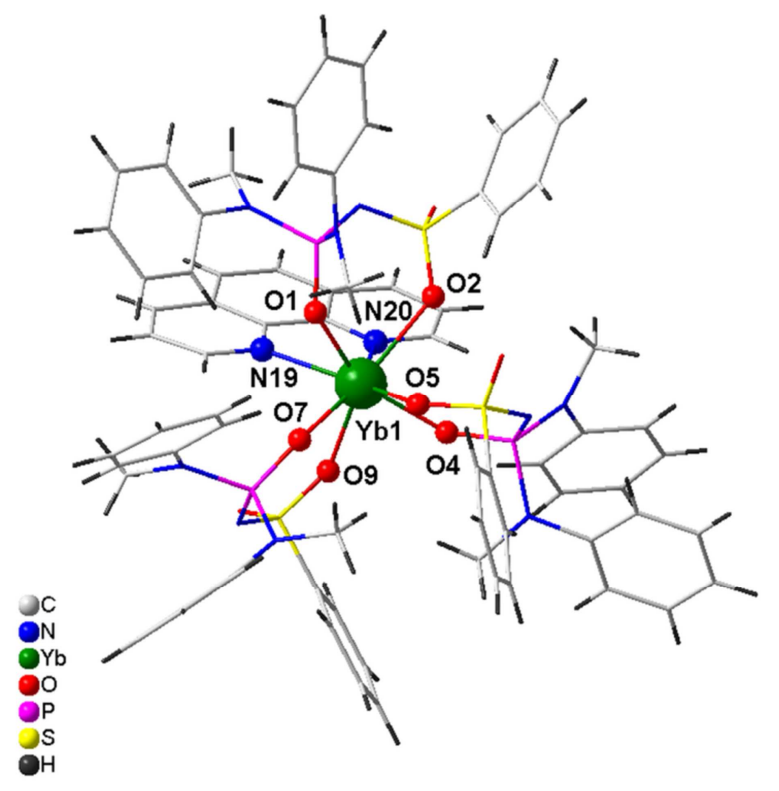

Figure 1. Molecular structure of $[\mathrm{Yb}(\mathrm{L})($ phen $)] \cdot 0.5 \mathrm{H}_{2} \mathrm{O}$, 5. Selected bond lengths in A: N19-Yb1, 2.525(2); N20-Yb1, 2.502(2); Yb1-O1, 2.217(2); Yb1-O2, 2.431(2); Yb1-O4, 2.224(2) ; Yb1-O5, 2.377(2) ; Yb1-O7, 2.225(2); Yb1-O9, 2.376(2).

Magnetic properties. The static dc magnetic properties of all the complexes measured at 1000 Oe are characteristic of mononuclear lanthanide complexes (Figure 2). The experimental $\chi_{\mathrm{M}} T$ values at $300 \mathrm{~K}$ equal 11.91 (expected for $\mathrm{Tb}^{\mathrm{III}}, 11.82,4 f^{8}, J=6, S=3, L=3, g_{6}=3 / 2$ ), 14.19 (Dy $\left.{ }^{\mathrm{III}}, 14.17,4 f^{9}, J=15 / 2, S=5 / 2, L=5, g_{15 / 2}=4 / 3\right), 14.07\left(\mathrm{Ho}^{\mathrm{III}}, 14.07,4 f^{10}, J=8, S=2, L=6\right.$, $\left.g_{8}=5 / 4\right), 11.57\left(\mathrm{Er}^{\mathrm{III}}, 11.48,4 f^{11}, J=15 / 2, S=3 / 2, L=6, g_{15 / 2}=6 / 5\right)$ and $2.73\left(\mathrm{Yb}^{\mathrm{III}}, 2.57,4 f^{13}, J\right.$ $\left.=7 / 2, S=1 / 2, L=3, g_{7 / 2}=8.7\right) \mathrm{cm}^{3} \mathrm{~K} \mathrm{~mol}^{-1}$, respectively for $\mathbf{1 - 5}$ and match well with the theoretical ones indicated in parentheses with the electronic configuration of the ground state. Upon cooling, the $\chi_{\mathrm{M}} T$ product of $\mathbf{1 - 3}$ slowly decrease until $15 \mathrm{~K}$ and more rapidly below to reach respectively $9.44,11.76$, and $11.80 \mathrm{~cm}^{3} \mathrm{~K} \mathrm{~mol}^{-1}$ for $2 \mathrm{~K}$. For 4 , the more pronounced decrease is observed below $100 \mathrm{~K}$ and reaches $7.26 \mathrm{~cm}^{3} \mathrm{~K} \mathrm{~mol}^{-1}$ for $2 \mathrm{~K}$. In the case of $\mathbf{5}$, the temperature dependence is smoother over the whole temperature range reaching $1.29 \mathrm{~cm}^{3} \mathrm{~K} \mathrm{~mol}^{-1}$ at $2 \mathrm{~K}$. 

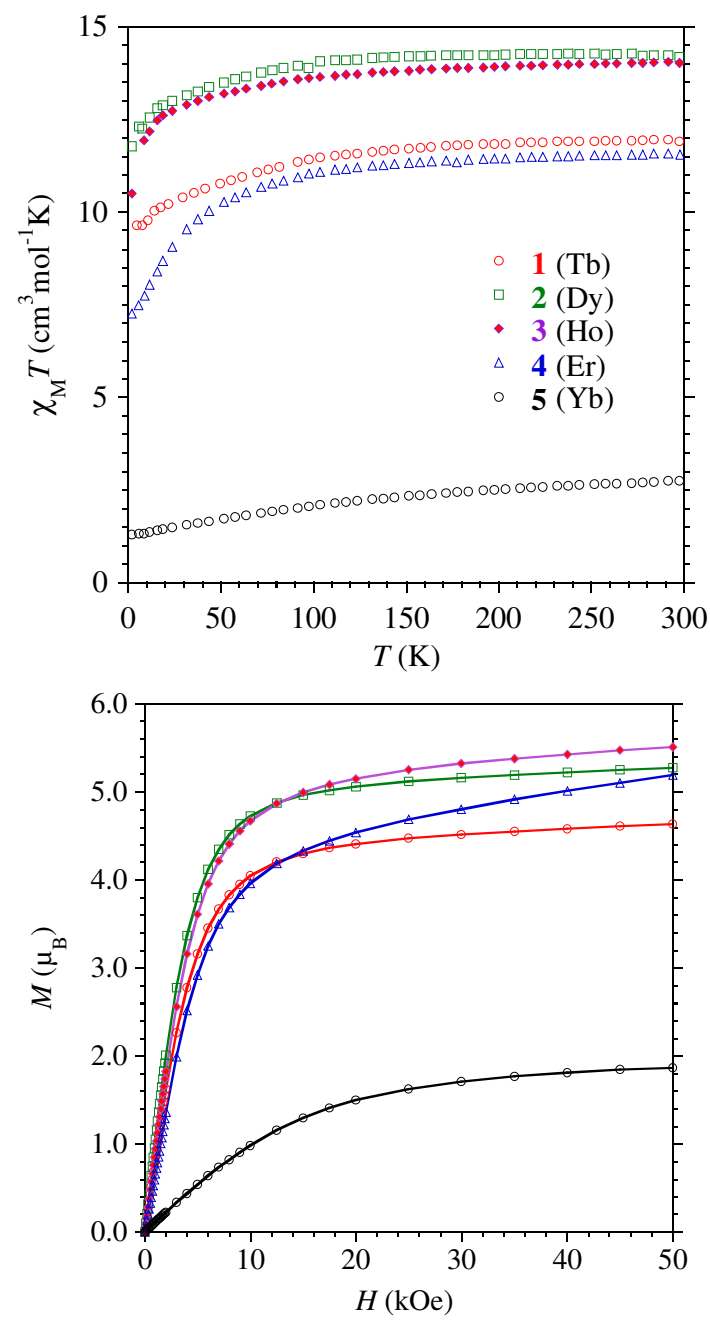

Figure 2. Experimental temperature dependence of $\chi_{\mathrm{M}} T$ (top) and field dependence of the magnetizations at $2 \mathrm{~K}$ (bottom) for the complexes 1-5. The solid lines are eyeguides.

The magnetization $(M)$ as a function of the field $(H)$ at $2 \mathrm{~K}$ for each compound is characterized by a fast increase for low field followed by a more gradual but steady increase up to $50 \mathrm{kOe}$ where values of $4.63(\mathbf{1}), 5.27(\mathbf{2}), 5.51(3), 5.19(4)$, and $1.86 \mu_{\mathrm{B}}(\mathbf{5})$ have been obtained.

The presence of slow relaxing magnetization was probed by ac magnetic measurements. In zero field only the Dy derivative showed a $\chi_{\mathrm{M}}$ "' signal but without maximum above $2 \mathrm{~K}$ whereas under an applied field of 1000 Oe, 2 and $\mathbf{4}$ exhibited frequency dependent ac maxima. At this field, the measurements of the ac signals at various frequencies between 10 and $1500 \mathrm{~Hz}$ allowed 
extracting the relaxation time $(\tau)$ at each temperatures (between 5 and $9 \mathrm{~K}$ for 2 and 2 and $3.1 \mathrm{~K}$ for 4) by fits of the $\chi_{\mathrm{M}}$ " $v s$. frequency with a generalized Debye model. ${ }^{[44]} \mathrm{A}$ rather linear variation for $\ln \tau=\mathrm{f}\left(T^{1}\right)$ was obtained for both derivatives (Fig. 3 and SI6). From a structural view point neither the Dy(III) nor the $\operatorname{Er}(\mathrm{III})$ ion is in a crystal field environment that would favor a highly anisotropic ground state ${ }^{[45]}$ Consequently just a thermally-assisted relaxation of the magnetization (Orbach process) is unlikely and, in any case could not apply for both metals because of the respective oblate and prolate electronic cloud for their lowest $J$ state. A related situation has been reported showing that a multi-process was at the origin of the slow magnetic relaxation for these ions. ${ }^{[46]}$ For $\mathbf{2}$, no satisfactory fit was obtained when considering Raman, or a combination of Raman and direct or Raman and Orbach processes; however, a good fit of the thermal dependence of $\tau$ was obtained with Arrhenius law, which was improved at the lower T by adding a contribution of QTM. Best fit gave an energy barriers of $\mathrm{U}_{\text {eff }} / \mathrm{k}_{\mathrm{B}}=46.7 \pm 5 \mathrm{~K}$ with $\tau_{0}=$ $8.3 \pm 0.4 \times 10^{-7} \mathrm{~s}$, and a QTM time of $9 \pm 1 \times 10^{-3} \mathrm{~s}$. For Er derivative 4, the narrow temperature range and linear behavior of $\tau$ renders discrimination between possible relaxation processes difficult. For this compound good fit were obtained for a Raman process $\left(\tau^{-1}=C \cdot T^{\mathrm{n}}\right.$, with $\mathrm{C}=$ $0.96 \pm 0.08, \mathrm{n}=8.48 \pm 0.08$ ) but also for Arrhenius equation (Figure SI6). For the latter, the obtained parameters are $\mathrm{U}_{\text {eff }} / \mathrm{k}_{\mathrm{B}}=22 \mathrm{~K}$ with $\tau_{0}=7.7 \times 10^{-8} \mathrm{~s}$ but keeping in mind the comments above, the fit parameters must be considered as purely phenomenological.
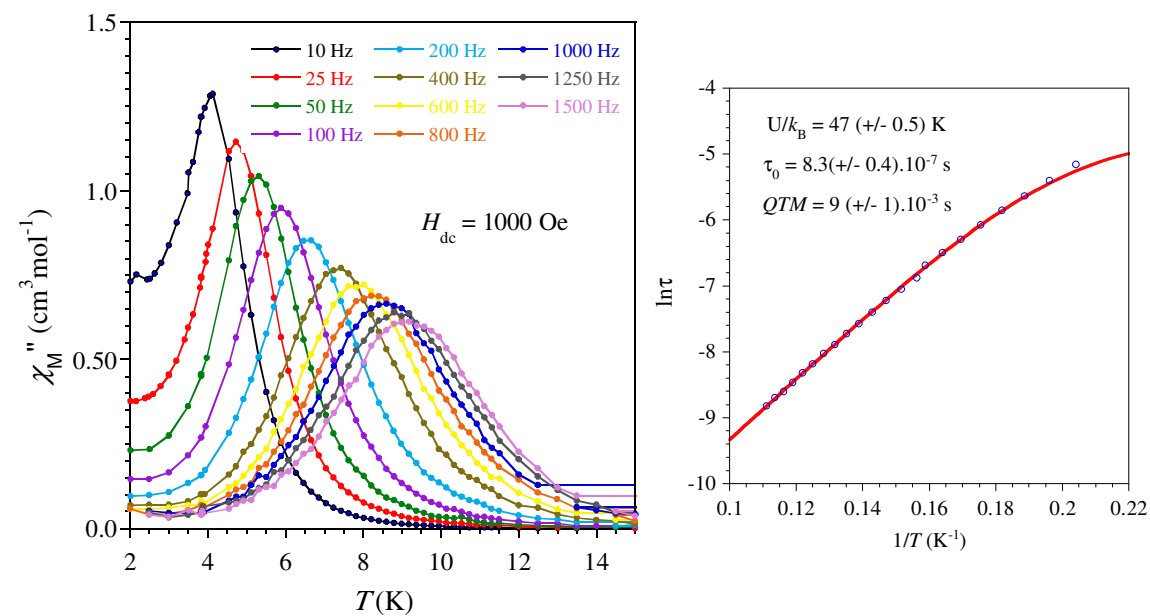

Figure 3. (left) Frequency dependence of the out-of-phase component of the ac susceptibility of $\mathbf{2}$ with an applied field of 1000 Oe, and (right) temperature 
dependence of the relaxation time with best fit (-) to an Arrhenius law with a contribution of QTM.

The Cole-Cole plots were also constructed from the ac magnetic susceptibility and fitted ${ }^{[47]}$ to extract the isothermal susceptibility $\left(\chi_{\mathrm{T}}\right)$, adiabatic susceptibility $\left(\chi_{\mathrm{S}}\right)$, the relaxation time $\tau$ and its distribution width $\alpha$ (Figures SI4 and SI7). The energy barrier of the Dy complex (2) falls in the range of values found in $\left[\mathrm{Dy}(\mathrm{L})\left(\mathrm{L}^{\prime}\right)\right]$ complexes $\left(\mathrm{L}=\beta\right.$-diketone and $\mathrm{L}^{\prime}=$ bipy or phen). ${ }^{[26-29 \text {, }}$ ${ }^{32,34]}$ No example of $\beta$-diketone Er derivative was found in the literature.

\section{CONCLUDING REMARKS}

An anionic sulphonyl-amidophosphate derivative is shown to be a good ligand in the preparation of isomorphous mononuclear lanthanide complexes. This ligand was found to coordinate the Ln centers by the means of oxygen atoms of its $\mathrm{PO}$ and $\mathrm{SO}$ moieties, thus behaving as a [O-O] chelate. In the series of derivatives reported herein, three such ligands coordinate the $\mathrm{Ln}^{\mathrm{III}}$ ion. Due to their bulkiness, the paramagnetic centers are well isolated within the crystal lattice, a situation favorable for the observation of slow relaxation of the magnetization (i.e. SMM behavior). Such a behavior was indeed found for the Dy (2) and $\operatorname{Er}(\mathbf{4})$ derivative.

\section{EXPERIMENTAL SECTION.}

Syntheses. All reagents and solvents were used as received from commercial sources. The ligand NaL was synthesized according to a previously described method. ${ }^{[40,48]}$

[ $\mathrm{LnL}_{3}$ (phen)] $0.5 \mathrm{H}_{2} \mathrm{O}$. All the compounds were prepared following the same procedure: A MeOH solution (5 mL) containing NaL (131 mg; $0.3 \mathrm{mmol}$ ) and phenantroline (54 mg; $0.1 \mathrm{mmol})$ was added to a solution of hydrated $\mathrm{Ln}\left(\mathrm{NO}_{3}\right)_{3}(0.1 \mathrm{mmol})$ in $\mathrm{MeOH}(5 \mathrm{~mL})$. A white solid formed within a few hours, which was filtered and dried. This powder was dissolved in acetone and layered with $\mathrm{Et}_{2} \mathrm{O}$ resulting in needle-like crystals of the Ln complex within a few days. 
[TbL $L_{3}$ (phen)] $0.5 \mathrm{H}_{2} \mathrm{O}$, 1. Yield: $0.153 \mathrm{~g}(96 \%)$. Anal. Calcd for $\mathrm{C}_{72} \mathrm{H}_{72} \mathrm{~N}_{11} \mathrm{O}_{9.5} \mathrm{P}_{3} \mathrm{~S}_{3} \mathrm{~Tb}: \mathrm{C}, 54.34$; H, 4.56; N, 9.68. Found: C, 53.91; H, 3.92; N, 9.61. IR (ATR diamond, $\mathrm{cm}^{-1}$ ): 3060 (m), 3030 (w), 2943 (w), 2904 (w), 2886 (w), 2819 (w), 1626 (w), 1599 (m), 1585 (sh), 1521 (w), 1494 (m), 1481 (sh), 1446 (m), 1427 (m), 1350 (w), 1243 (m), 1188 (m), 1162 (m), 1125 (s), 1088 (m), 1065 (m), 1028 (m), 998 (w), 891 (m), 864 (sh), 844 (w), 802 (w), 754 (m), 730 (w), $711(w)$, $690(\mathrm{~m}), 638(\mathrm{w}), 612(\mathrm{~m})$.

[DyL $L_{3}$ (phen)]·0.5 $\mathrm{H}_{2} \mathrm{O}, 2$. Yield: $0.157 \mathrm{~g}(98 \%)$. Anal. Calcd. for $\mathrm{C}_{72} \mathrm{H}_{72} \mathrm{~N}_{11} \mathrm{O}_{9.5} \mathrm{P}_{3} \mathrm{~S}_{3} \mathrm{Dy}$ : C, 54.22; H, 4.54; N, 9.66. Found: C, 54.2; H, 3.91; N, 9.58. IR (ATR diamond, $\mathrm{cm}^{-1}$ ): 3060 (m), 3034 (w), 2950 (w), 2901 (w), 2887 (w), 2820 (w), 1629 (w), 1598 (m), 1585 (sh), 1518 (w), 1494 (m), 1481 (sh), 1446 (m), 1425 (m), 1381 (w), 1350 (w), 1244 (m), 1189 (m), 1165 (m), 1130 (s), 1089 (m), 1066 (m), 1029 (m), 999 (w), 894 (m), 866 (sh), 846 (w), 805 (w), 755 (m), 730 (w), $724(\mathrm{w}), 712(\mathrm{w}), 691(\mathrm{~m}), 637(\mathrm{w}), 613(\mathrm{~m})$.

[HoL $\mathrm{H}_{3}$ (phen)] $0.5 \mathrm{H}_{2} \mathrm{O}, 3$. Yield: $0.149 \mathrm{~g}(93 \%)$. Anal. Calcd. for $\mathrm{C}_{72} \mathrm{H}_{72} \mathrm{~N}_{11} \mathrm{O}_{9.5} \mathrm{P}_{3} \mathrm{~S}_{3} \mathrm{Ho}: \mathrm{C}, 54.13$; H, 4.54; N, 9.64. Found: C, 53.90; H, 4.10; N, 9.60. IR (ATR diamond, $\mathrm{cm}^{-1}$ ): 3060 (m), 3029 (w), 2959 (w), 2904 (w), 2884 (w), 2820 (w), 1629 (w), 1597 (m), 1585 (sh), 1518 (w), 1494 (m), 1446 (m), 1425 (m), 1382 (w), 1350 (w), 1244 (m), 1184 (m), 1167 (m), 1123 (s), 1088 (m), 1063 (m), 1027 (m), 998 (w), 953 (m), 890 (m), 866 (sh), 844 (w), 807 (w), 752 (m), 729 (w), $721(\mathrm{w}), 714(\mathrm{w}), 688(\mathrm{~m}), 637(\mathrm{w}), 611(\mathrm{~m})$.

[ErL $L_{3}$ (phen)]·0.5 $\mathrm{H}_{2} \mathrm{O}, 4$. Yield: $0.155 \mathrm{~g}(97 \%)$. Anal. Calcd. for $\mathrm{C}_{72} \mathrm{H}_{72} \mathrm{~N}_{11} \mathrm{O}_{9.5} \mathrm{P}_{3} \mathrm{~S}_{3} \mathrm{Er}: \mathrm{C}, 54.05$; H, 4.54; N, 9.63. Found: C, 53.59; H, 4.0; N, 9.50. IR (ATR diamond, $\mathrm{cm}^{-1}$ ): 3051 (m), 3029 (w), 2952 (w), 2904 (w), 2884 (w), 2820 (w), 1629 (w), 1597 (m), 1585 (sh), 1518 (w), 1494 (m), 1446 (m), 1425 (m), 1347 (w), 1243 (m), 1185 (m), 1167 (m), 1125 (s), 1089 (m), 1063 (m), 1027 (m), 998 (w), $889(\mathrm{~m}), 844(\mathrm{w}), 807$ (w), $752(\mathrm{~m}), 714$ (w), $688(\mathrm{~m}), 612(\mathrm{~m})$.

[YbL $\mathrm{Yb}_{3}$ (phen)]·0.5 $\mathrm{H}_{2} \mathrm{O}$, 5. Yield: $0.148 \mathrm{~g}(92 \%)$. Anal. Calcd. for $\mathrm{C}_{72} \mathrm{H}_{72} \mathrm{~N}_{11} \mathrm{O}_{9.5} \mathrm{P}_{3} \mathrm{~S}_{3} \mathrm{Yb}: \mathrm{C}, 53.9$; H, 4.52; N, 9.60. Found: C, 54.2; H, 3.9; N, 9.5. IR (ATR diamond, $\mathrm{cm}^{-1}$ ): 3229 (b), 3061 (m), 2949 (w), 2908 (w), 2887 (w), 2822 (w), 1712 (w), 1628 (w), 1599 (m), 1522 (w), 1494 (s), 1447 (m), 1427 (m), 1372 (w), 1293 (sh), 1243 (m), 1186 (sh), 1169 (m), 1129 (s), 1083 (m), 1065 (m), 1029 (m), 998 (w), 894 (m), 856 (sh), 845 (w), 806 (w), 754 (m), 730 (w), 712 (w), 689 (m), 640(w), $613(w)$. 
Fourier transform infrared (FT-IR) spectroscopy was performed with a Perkin-Elmer spectrum GX 2000 FT-IR spectrometer. Elemental analyses were performed with a Perkin-Elmer 2400 series II instrument. Magnetic susceptibility measurements were carried out with a Quantum Design MPMS-5S SQUID magnetometer. The magnetic studies were performed on freshly isolated polycrystalline powders mixed with grease and put in gelatin capsules. Data have been collected between 300 and $2 \mathrm{~K}$ with an applied field of $1 \mathrm{kOe}$ and corrected for the diamagnetic contribution sample by using Pascal's tables ${ }^{[49]}$ and for the sample holder. The field dependences of the magnetization were measured at $2 \mathrm{~K}$ with dc magnetic field up to $5 \mathrm{~T}$.

Single-crystal X-ray diffraction: Single crystals suitable for X-ray diffraction were coated with paratone oil and mounted onto the goniometer. The X-ray crystallographic data were obtained at low temperature from a Gemini Oxford (for 5) or a Bruker Apex2 (for 2) diffractometer (MoK $\alpha$ radiation source) equipped with an Oxford Cryosystem. The structures have been solved with Superflip and refined by means of least-square procedures on $\mathrm{F}$ using the PC version of the program CRYSTALS. ${ }^{[50]}$ The scattering factors for all the atoms were used as listed in the International Tables for X-ray Crystallography. ${ }^{[51]}$ Absorption correction was performed using a multi-scan procedure. All non-hydrogen atoms were refined anisotropically. When it was possible, the $\mathrm{H}$ atoms were located in a difference map, but those attached to carbon atoms were repositioned geometrically. The $\mathrm{H}$ atoms were initially refined with soft restraints on the bond lengths and angles to regularise their geometry and $\mathrm{U}$ iso $(\mathrm{H})$ (in the range 1.2-1.5 times $\mathrm{U}$ eq of the parent atom), after which the positions were refined with riding constraints. Crystallographic data are gathered in Table 1. Crystals for $\mathbf{2}$ were poorly diffracting resulting in a refinement of limited quality but structure is ascertained. The cif for $\mathbf{5}$ has been deposited at CCDC with reference number 1951981. 
Table 1. Selected crystallographic data and refinement parameters of $\mathbf{1}-\mathbf{5}$

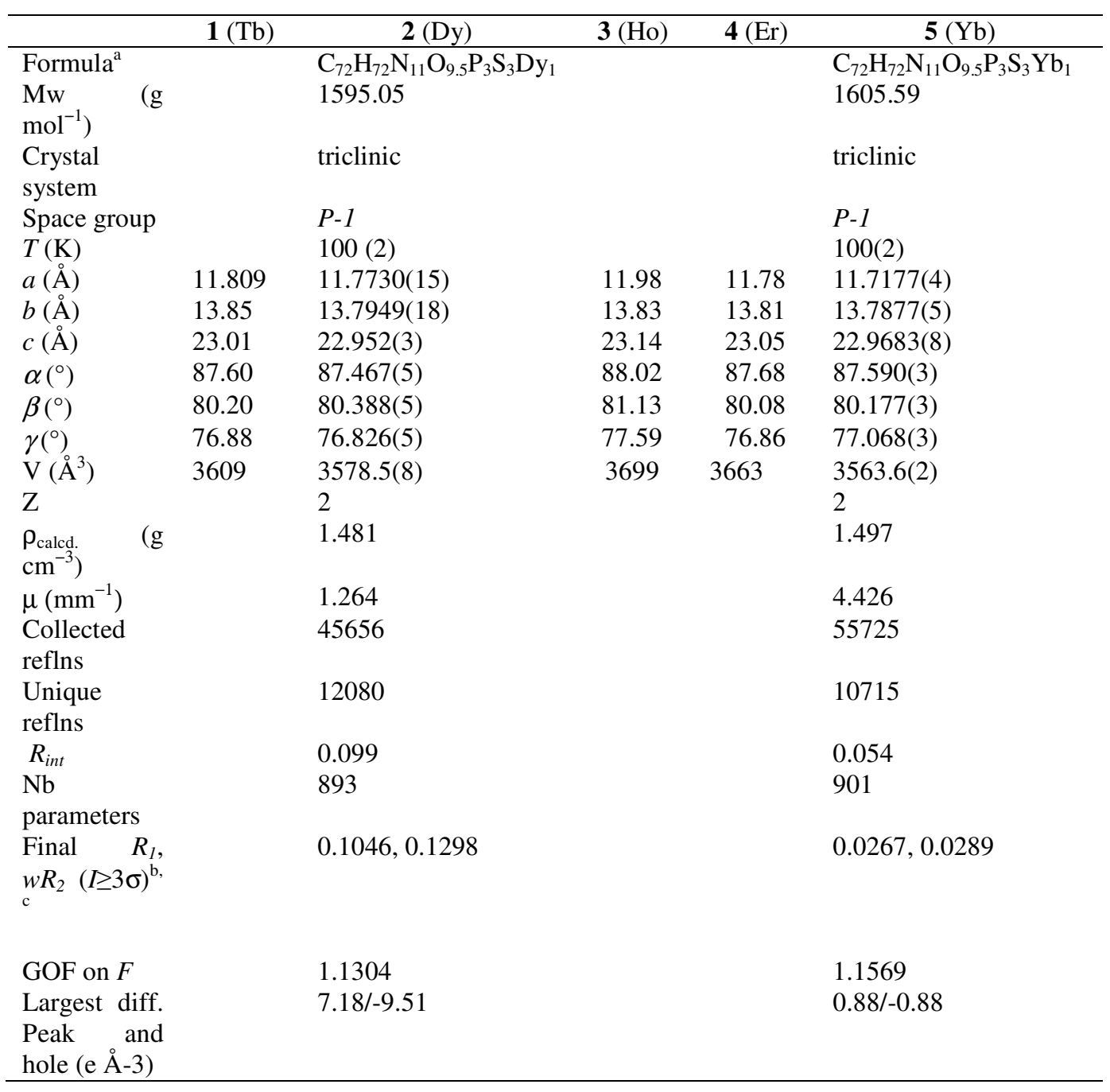

${ }^{a} R_{1}=\Sigma|| F_{\mathrm{o}}|-| F_{\mathrm{c}}|| \Sigma\left|F_{\mathrm{o}}\right|,{ }^{c} w R_{2}=\left[\Sigma\left(w\left(F_{\mathrm{o}}{ }^{2}-F_{\mathrm{c}}\right)^{2}\right) / \Sigma\left(\left[w\left(F_{\mathrm{o}}{ }^{2}\right)^{2}\right]^{1 / 2}\right.\right.$ where $w=1 /\left(\sigma^{2}\left(F_{\mathrm{o}}{ }^{2}\right)+(a P)^{2}+b P\right)$ with $P=\left(2 F_{\mathrm{c}}{ }^{2}+\right.$ $\left.\max \left(F_{\mathrm{o}}^{2}, 0\right)\right) / 3$.

\section{ACKNOWLEDGEMENTS}

A.Y.P.K. is grateful to the French Embassy in Ukraine for a research internship grant; M.M. J.-F.

Meunier and L. Rechignat are acknowledged for technical assistance in magnetic measurements. 


\section{REFERENCES}

[1] C. Milios, R. P. Winpenny, in Molecular Nanomagnets and Related Phenomena, Vol. 164 (Ed.: S. Gao), Springer Berlin Heidelberg, 2015, pp. 1-109.

[2] N. Ishikawa, M. Sugita, T. Ishikawa, S.-y. Koshihara, K. Youkoh, J. Am. Chem. Soc. 2003, 125, 8694-8695.

[3] F.-S. Guo, B. M. Day, Y.-C. Chen, M.-L. Tong, A. Mansikkamäki, R. A. Layfield, Science 2018, 362, 1400-1403.

[4] R. J. Holmberg, M. Murugesu, J. Mater. Chem. C 2015, 3, 11986-11998.

[5] D. Mitcov, A. H. Pedersen, M. Ceccato, R. M. Gelardi, T. Hassenkam, A. Konstantatos, A. Reinholdt, M. A. Sørensen, P. W. Thulstrup, M. G. Vinum, F. Wilhelm, A. Rogalev, W. Wernsdorfer, E. K. Brechin, S. Piligkos, Chem. Sci. 2019, 10, 3065-3073.

[6] S. Sanvito, Chem. Soc. Rev. 2011, 40, 3336-3355.

[7] K. Katoh, H. Isshiki, T. Komeda, M. Yamashita, Coord. Chem. Rev. 2011, 255, 2124-2148.

[8] A. Chiesa, G. F. S. Whitehead, S. Carretta, L. Carthy, G. A. Timco, S. J. Teat, G. Amoretti, E. Pavarini, R. E. P. Winpenny, P. Santini, Sci. Rep. 2014, 4.

[9] J. D. Rinehart, K. R. Meihaus, J. R. Long, J. Am. Chem. Soc. 2010, 132, 7572-7573.

[10] D. N. Woodruff, R. E. P. Winpenny, R. A. Layfield, Chem. Rev. 2013, 113, 5110-5148.

[11] R. A. Layfield, Organometallics 2014, 33, 1084-1099.

[12] F.-S. Guo, A. K. Bar, R. A. Layfield, Chem. Rev. 2019, 119, 8479-8505.

[13] S. G. McAdams, A.-M. Ariciu, A. K. Kostopoulos, J. P. S. Walsh, F. Tuna, Coord. Chem. Rev. 2017, 346, 216-239.

[14] Z. Zhu, M. Guo, X.-L. Li, J. Tang, Coord. Chem. Rev. 2019, 378, 350-364.

[15] M. Gonidec, D. B. Amabilino, J. Veciana, Dalton Trans. 2012, 41, 13632-13639.

[16] G. Cucinotta, M. Perfetti, J. Luzon, M. Etienne, P.-E. Car, A. Caneschi, G. Calvez, K. Bernot, R. Sessoli, Angew. Chem. Int. Ed. 2012, 51, 1606-1610.

[17] D.-P. Li, T.-W. Wang, C.-H. Li, D.-S. Liu, Y.-Z. Li, X.-Z. You, Chem. Commun. 2010, 46, 2929-2931.

[18] F. R. Fortea-Pérez, J. Vallejo, M. Julve, F. Lloret, G. D. Munno, D. Armentano, E. Pardo, Inorg. Chem. 2013, 52, 4777-4779.

[19] D. Zeng, M. Ren, S.-S. Bao, L.-M. Zheng, Inorg. Chem. 2014, 53, 795-801.

[20] W.-B. Sun, B. Yan, Y.-Q. Zhang, B.-W. Wang, Z.-M. Wang, J.-H. Jia, S. Gao, Inorg. Chem. Front. 2014, 1, 503-509.

[21] P. Martín-Ramos, M. Ramos Silva, J. T. Coutinho, L. C. J. Pereira, P. Chamorro-Posada, J. MartínGil, Eur. J. Inorg. Chem. 2014, 2014, 511-517.

[22] M. Ramos Silva, P. Martín-Ramos, J. T. Coutinho, L. C. J. Pereira, V. Lavín, I. R. Martín, P. S. P.S., J. Martín-Gil, Dalton Trans. 2015, 44, 1264-1272.

[23] S. Zhang, W. Mo, Z. Zhang, F. Gao, L. Wang, D. Hu, S. Chen, Dalton Trans. 2019, 48, 12466-12481.

[24] K. Bernot, J. Luzon, L. Bogani, M. Etienne, C. Sangregorio, M. Shanmugam, A. Caneschi, R. Sessoli, D. Gatteschi, J. Am. Chem. Soc. 2009, 131, 5573-5579.

[25] F. Pointillart, K. Bernot, S. Golhen, B. Le Guennic, T. Guizouarn, L. Ouahab, O. Cador, Angew. Chem. Int. Ed. 2015, 54, 1504-1507.

[26] Y. Bi , Y.-N. Guo, L. Zhao, Y. Guo, S.-Y. Lin, S.-D. Jiang, J. Tang, B.-W. Wang, S. Gao, Chem. Eur. J. 2011, 17, 12476-12481.

[27] Y. Dong, P. Yan, X. Zou, G. Li, Inorg. Chem. Front. 2015, 2, 827-836.

[28] J. Zhu, C. Wang, F. Luan, T. Liu, P. Yan, G. Li, Inorg. Chem. 2014, 53, 8895-8901.

[29] C.-M. Liu, D.-Q. Zhang, D.-B. Zhu, Inorg. Chem. 2013, 52, 8933-8940.

[30] Y.-L. Wang, Y. Ma, X. Yang, J. Tang, P. Cheng, Q.-L. Wang, L.-C. Li, D.-Z. Liao, Inorg. Chem. 2013, $52,7380-7386$. 
[31] K. Qian, J. J. Baldovi, S.-D. Jiang, A. Gaita-Arino, Y.-Q. Zhang, J. Overgaard, B.-W. Wang, E. Coronado, S. Gao, Chem. Sci. 2015, 6, 4587-4593.

[32] G.-J. Chen, C.-Y. Gao, J.-L. Tian, J. Tang, W. Gu, X. Liu, S.-P. Yan, D.-Z. Liao, P. Cheng, Dalton Trans. 2011, 40, 5579-5583.

[33] Y. Dong, P. Yan, X. Zou, X. Yao, G. Hou, G. Li, Dalton Trans. 2016, 45, 9148-9157.

[34] P.-P. Cen, S. Zhang, X.-Y. Liu, W.-M. Song, Y.-Q. Zhang, G. Xie, S.-P. Chen, Inorg. Chem. 2017, 56, 3644-3656.

[35] C. Maxim, D. G. Branzea, C. Tiseanu, M. Rouzières, R. Clérac, M. Andruh, N. Avarvari, Inorg. Chem. 2014, 53, 2708-2717.

[36] Amirkhanov V.M., Ovchynnikov V.A., V. A. Trush, Gawryszewska P., , J. L.B., in Ligands. Synthesis, Characterization and Role in Biotechnology (Eds.: G. P., S. P.), NOVA Publishers, New York, 2014, pp. 199-248.

[37] O. V. Moroz, V. A. Trush, T. Y. Sliva, K. O. Znovjyak, V. M. Amirkhanov, Acta Cryst. E 2014, 70, m209-m210.

[38] P. Gawryszewska, O. V. Moroz, V. A. Trush, V. M. Amirkhanov, T. Lis, M. Sobczyk, M. Siczek, ChemPlusChem 2012, 77, 482-496.

[39] P. Gawryszewska, V. M. Amirkhanov, V. A. Trush, D. Kulesza, J. Legendziewicz, J. Lum. 2016, 170, 340-347.

[40] A. Y. Prytula-Kurkunova, V. A. Trush, V. V. Dyakonenko, T. Y. Sliva, V. M. Amirkhanov, Acta Cryst. E 2017, 73, 1076-1081.

[41] S. Alvarez, P. Alemany, D. Casanova, J. Cirera, M. Llunell, D. Avnir, Coord. Chem. Rev. 2005, 249, $1693-1708$.

[42] D. Casanova, M. Llunell, P. Alemany, S. Alvarez, Chem. Eur. J. 2005, 11, 1479-1494.

[43] M. C. Llunell, D.; Cirera, J.; Alemany, P.; Alvarez, S., Shape program, version 2; Universitat de Barcelona: Barcelona, Spain 2010.

[44] C. Dekker, A. F. M. Arts, H. W. de Wijn, A. J. van Duyneveldt, J. A. Mydosh, Phys. Rev. B 1989, 40, 11243-11251.

[45] J. D. Rinehart, J. R. Long, Chem. Sci. 2011, 2, 2078.

[46] E. Lucaccini, L. Sorace, M. Perfetti, J.-P. Costes, R. Sessoli, Chem. Comm. 2014, 50, 1648-1651.

[47] K. S. Cole, R. H. Cole, J. Chem. Phys. 1941, 9, 341-351.

[48] V. V. Skopenko, O. V. Moroz, V. O. Trush, E. A. Trush, V. M. Amirkhanov, Rep. Nat. Acad. Sci. Ukr. 2008, 10, 160-165.

[49] O. Kahn, Molecular Magnetism, VCH, Weinheim, 1993.

[50] P. W. Betteridge, J. R. Carruthers, R. I. Cooper, K. Prout, D. J. Watkin, J. Appl. Cryst. 2003, 36, 1487.

[51] W. Schmitz, Krist. Tech. 1975, 10, K120-K120. 
Figure SI1. Molecular structure views for $[\mathrm{Dy}(\mathrm{L})(\mathrm{phen})] \cdot 0.5 \mathrm{H}_{2} \mathrm{O}, 2$.

Figure SI2. Molecular structure views for $[\mathrm{Yb}(\mathrm{L})(\mathrm{phen})] \cdot 0.5 \mathrm{H}_{2} \mathrm{O}, \mathbf{5}$.

Table SI1. Continuous Shape Measures calculations performed on 5.

Table SI2. Selected bond angles for 5.

Figure SI3. Frequency and temperature dependence of the in-phase $\left(\chi_{M}{ }^{\prime}\right)$ and out-ofphase $\left(\chi_{\mathrm{M}}{ }^{\prime \prime}\right)$ ac signals for $\mathbf{2}$.

Figure SI4. Cole-Cole plots for 2.

Figure SI5. Frequency and temperature dependence of the in-phase $\left(\chi_{M}{ }^{\prime}\right)$ and out-ofphase $\left(\chi_{\mathrm{M}}{ }^{\prime \prime}\right)$ ac signals for $\mathbf{5}$.

Figure SI6.Analyses of the relaxation time for 4.

Figure SI7. Cole-Cole plots for 4.

Figure SI1. Molecular structure of $[\mathrm{Dy}(\mathrm{L})(\mathrm{phen})] \cdot 0.5 \mathrm{H}_{2} \mathrm{O}, 2$.

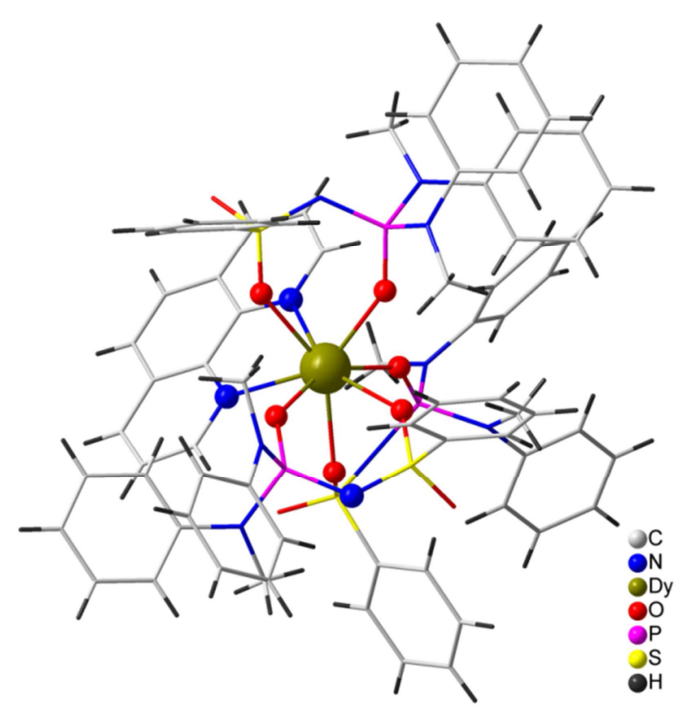


Figure SI2. (a) Asymmetric unit of $[\mathrm{Yb}(\mathrm{L})($ phen $)] \cdot 0.5 \mathrm{H}_{2} \mathrm{O}, 5$ with thermal ellipsoids fixed at $30 \%$. (b) Representation of the $\mathrm{Yb}(\mathrm{III})$ coordination sphere in 5. (c) View of the dimeric unit generated by $\pi \cdots \pi$ interaction. Crystal packing of $\mathbf{5}$ in the (d) $(b, c)$ and (e) $(a, c)$ plane. The dashed red lines materialize the shortest intermolecular metal-metal distance (indicated in $\AA$ ) while the dashed cyan line indicate the $\pi \cdots \pi$ interactions with the centroid to centroid distance indicated in $\AA$. Color scheme: $\mathrm{C}=$ grey, $\mathrm{H}=$ dark grey, $\mathrm{N}=$ blue, $\mathrm{O}=$ red, $\mathrm{S}=$ yellow, $\mathrm{P}=$ purple and $\mathrm{Yb}=$ green.

(a)

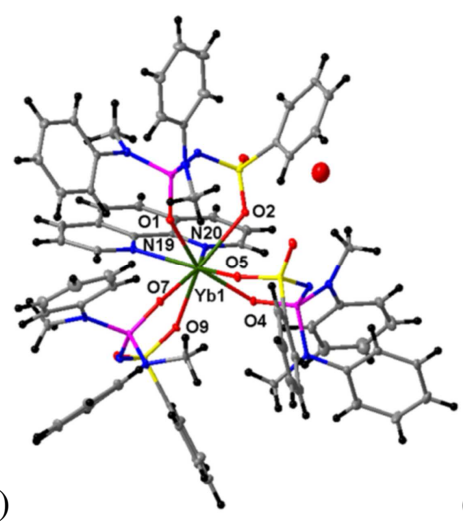

(b)

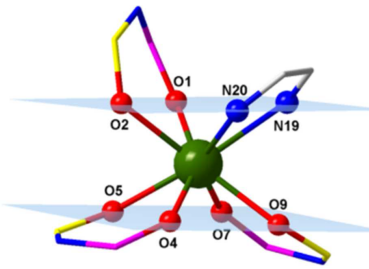

(c)

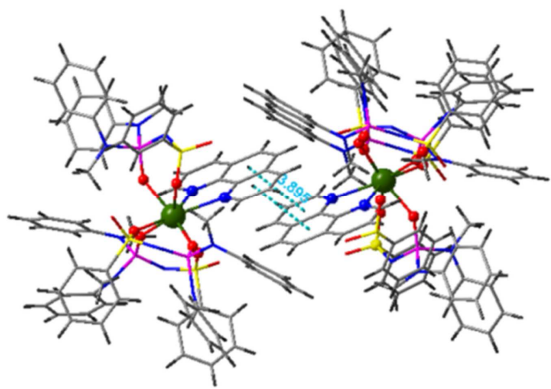

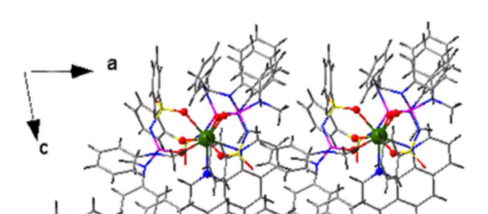

(d)

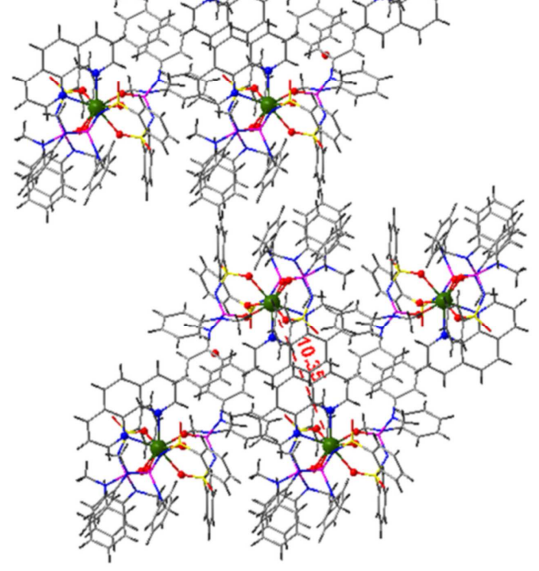

(e)

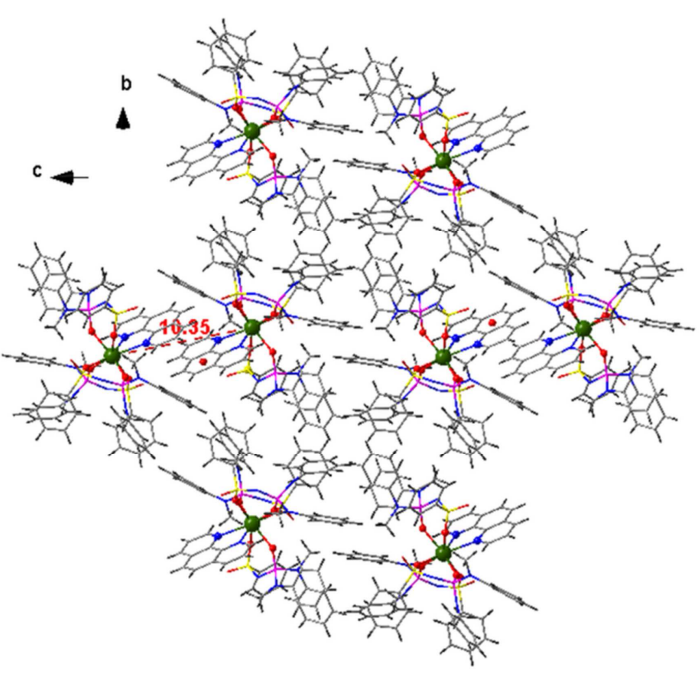


Table SI1. Results of Continuous Shape Measures calculation using SHAPE ${ }^{1}$ for the octacoordinated Yb complex. ${ }^{2}$ The ideal geometry closest to the actual shape of the coordination sphere is highlighted in blue.

\begin{tabular}{ccccc}
\hline Metal center & SAPR-8 & TDD-8 & JBTPR-8 & BTPR-8 \\
\hline Yb@5 & 0.721 & 2.217 & 2.943 & 2.676 \\
\hline
\end{tabular}

$\begin{array}{lll}\text { SAPR-8 } & 5 \mathrm{D} 4 \mathrm{~d} & \text { Square antiprism } \\ \text { TDD-8 } & 6 \mathrm{D} 2 \mathrm{~d} & \text { Triangular dodecahedron } \\ \text { JBTPR-8 } & 9 \mathrm{C} 2 \mathrm{v} & \text { Biaugmented trigonal prism J50 } \\ \text { BTPR-8 } & 10 \mathrm{C} 2 \mathrm{v} & \text { Biaugmented trigonal prism }\end{array}$

Table SI2. Selected bond angles of $5\left(^{\circ}\right)$.

$\begin{array}{llll}\text { N19-Yb1-N20 } & 64.87(6) & \text { N19-Yb1-O1 } & 72.23(6) \\ \text { N20-Yb1-O1 } & 109.89(6) & \text { N19-Yb1-O2 } & 109.52(6) \\ \text { N20-Yb1-O2 } & 71.70(6) & \text { O1-Yb1-O2 } & 74.16(6) \\ \text { N19-Yb1-O4 } & 134.51(6) & \text { N20-Yb1-O4 } & 78.31(6) \\ \text { O1-Yb1-O4 } & 149.39(6) & \text { O2-Yb1-O4 } & 81.18(6) \\ \text { N19-Yb1-O5 } & 150.84(6) & \text { N20-Yb1-O5 } & 140.77(6) \\ \text { O1-Yb1-O5 } & 83.01(6) & \text { O2-Yb1-O5 } & 77.08(6) \\ \text { O4-Yb1-O5 } & 73.90(6) & \text { N19-Yb1-O7 } & 86.37(6) \\ \text { N20-Yb1-O7 } & 145.01(6) & \text { O1-Yb1-O7 } & 77.00(6) \\ \text { O2-Yb1-O7 } & 140.41(6) & \text { O4-Yb1-O7 } & 113.77(6) \\ \text { N19-Yb1-O9 } & 145.01(6) & \text { N20-Yb1-O9 } & 80.32(6) \\ \text { O1-Yb1-O9 } & 136.37(6) & \text { O2-Yb1-O9 } & 145.29(5) \\ \text { O4-Yb1-O9 } & 73.24(6) & \text { O5-Yb1-O7 } & 72.97(6) \\ \text { O5-Yb1-O9 } & 116.35(6) & \text { O7-Yb1-O9 } & 72.92(6)\end{array}$

\footnotetext{
${ }^{1}$ Llunell, M.; Casanova, D.; Cirera, J.; Alemany, P.; Alvarez, S. SHAPE: Program for the stereochemical analysis of molecular fragments by means of continuous shape measures and associated tools, 2.1; University of Barcelona: Barcelona, 2013.

${ }^{2}$ D. Casanova, P. Alemany, J. M. Bofill, S. Alvarez, Chem. Eur. J., 2003, 9, 1281.
} 


\section{AC susceptibility investigations for $\left[\mathrm{Dy}(\mathrm{L})_{3}(\right.$ phen $\left.)\right] \cdot 0.5 \mathrm{H}_{2} \mathrm{O}, 2$ :}

Figure SI3. Compound 2:Temperature and frequency dependence of the in-phase $\left(\chi^{\prime}\right)$ and out-of-phase $\left(\chi^{\prime}\right)$ ac susceptibilities recorded at 1000 Oe dc field with a 3 Oe ac field with frequencies and temperatures ranging from 1 to $1500 \mathrm{~Hz}$ and 2 to $15 \mathrm{~K}$, respectively. The solid lines in $\chi_{\mathrm{M}}{ }^{\prime \prime}=\mathrm{f}(\mathrm{v})$ are the best-fits to the Debye model.
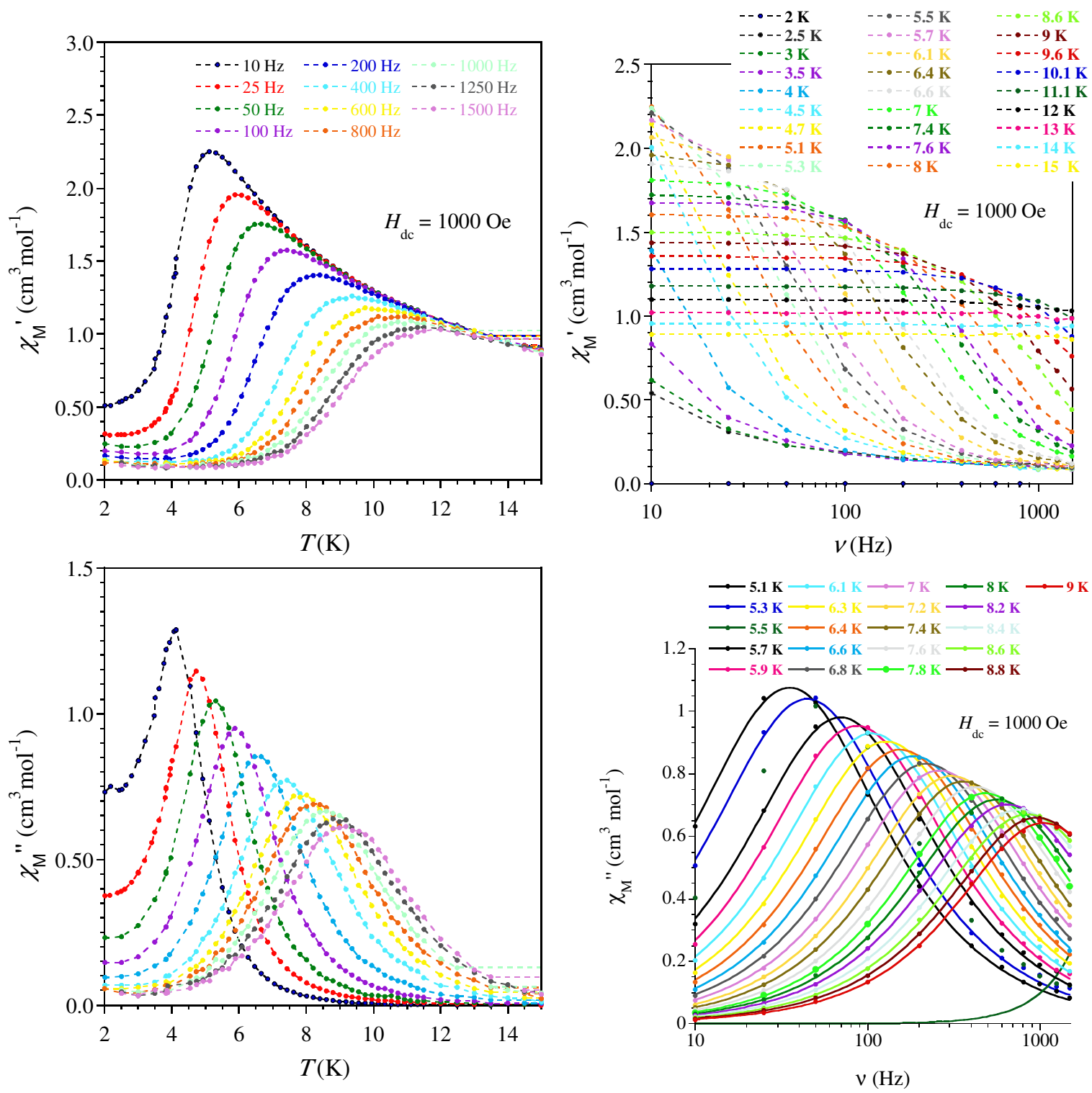
Figure SI4. Cole-Cole $\left(\chi_{\mathrm{M}}{ }^{\prime \prime}=\mathrm{f}\left(\chi_{\mathrm{M}}{ }^{\prime}\right)\right)$ plots for 2 between 2.5 and $9.9 \mathrm{~K}$ with the best fits to the generalized Debye model (equation 1$)^{3}$; best fit parameters are gathered in the table.

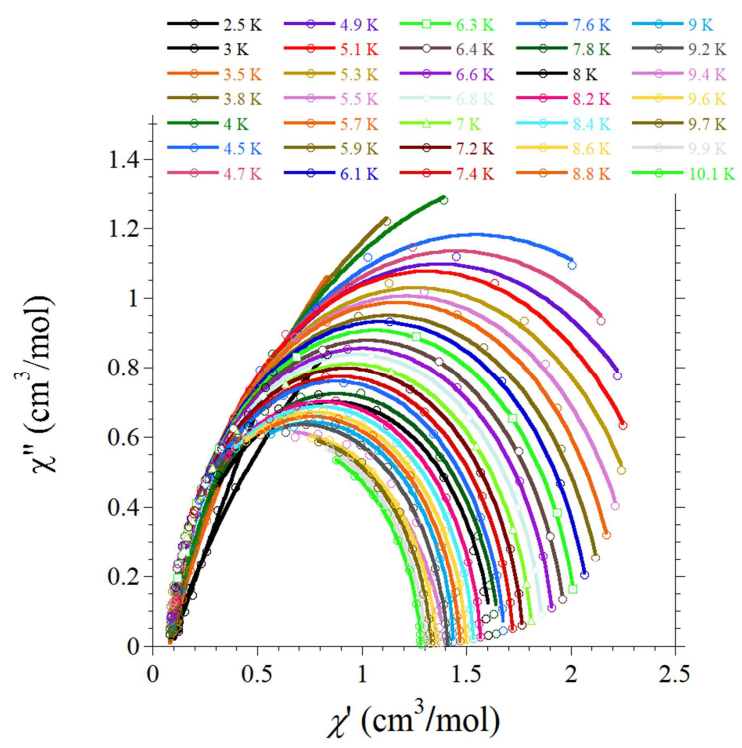

\begin{tabular}{|c|c|c|c|c|}
\hline$T(\mathrm{~K})$ & $\chi_{\mathrm{T}}\left(\mathrm{cm}^{3} \mathrm{~mol}^{-1}\right)$ & $\chi_{\mathrm{s}}\left(\mathrm{cm}^{3} \mathrm{~mol}^{-1}\right)$ & $\alpha$ & $R^{2}$ \\
\hline 2.5 & 8.8382 & 0.10688 & 0.27962 & 0.99975 \\
\hline 3 & 5.4992 & 0.10018 & 0.24248 & 0.99969 \\
\hline 3.5 & 4.3496 & 0.096175 & 0.20277 & 0.99980 \\
\hline 4 & 3.5536 & 0.090809 & 0.16310 & 0.99981 \\
\hline 4.5 & 2.9103 & 0.092897 & 0.10735 & 0.99976 \\
\hline 4.7 & 2.7503 & 0.093469 & 0.091846 & 0.99992 \\
\hline 4.9 & 2.6314 & 0.089909 & 0.084984 & 0.99918 \\
\hline 5.1 & 2.5273 & 0.088674 & 0.079353 & 0.99965 \\
\hline 5.3 & 2.4271 & 0.083195 & 0.073502 & 0.99919 \\
\hline 5.5 & 2.3348 & 0.086407 & 0.065082 & 0.99945 \\
\hline 5.7 & 2.2527 & 0.079132 & 0.061811 & 0.99947 \\
\hline 5.9 & 2.1798 & 0.074629 & 0.065216 & 0.99833 \\
\hline 6.1 & 2.1045 & 0.079698 & 0.052938 & 0.99941 \\
\hline 6.3 & 2.0366 & 0.083953 & 0.044911 & 0.99847 \\
\hline 6.4 & 1.9819 & 0.073236 & 0.053195 & 0.99938 \\
\hline 6.6 & 1.9239 & 0.074859 & 0.049721 & 0.99945 \\
\hline 6.8 & 1.8693 & 0.083829 & 0.040398 & 0.99958 \\
\hline 7 & 1.8179 & 0.081856 & 0.044056 & 0.99991 \\
\hline 7.2 & 1.7721 & 0.072073 & 0.040415 & 0.99958 \\
\hline 7.4 & 1.7269 & 0.069994 & 0.044151 & 0.99959 \\
\hline 7.6 & 1.6863 & 0.064039 & 0.044174 & 0.99922 \\
\hline 7.8 & 1.6431 & 0.070721 & 0.044792 & 0.99992 \\
\hline 8 & 1.6049 & 0.075611 & 0.039350 & 0.99943 \\
\hline 8.2 & 1.5704 & 0.061846 & 0.047385 & 0.99976 \\
\hline 8.4 & 1.5345 & 0.057962 & 0.046388 & 0.99991 \\
\hline 8.6 & 1.5008 & 0.051375 & 0.050697 & 0.99941 \\
\hline 8.8 & 1.4689 & 0.062169 & 0.042824 & 0.99955 \\
\hline 9 & 1.4421 & 0.072761 & 0.044556 & 0.9996 \\
\hline 9.2 & 1.4069 & 0.032139 & 0.044862 & 0.9996 \\
\hline 9.4 & 1.382 & 0.039877 & 0.047101 & 0.99917 \\
\hline 9.6 & 1.3560 & 0.045695 & 0.054776 & 0.99999 \\
\hline 9.7 & 1.3303 & 0.0077507 & 0.062403 & 0.99945 \\
\hline 9.9 & 1.3053 & 0.028990 & 0.054167 & 0.99952 \\
\hline
\end{tabular}

${ }^{3}$ K. S. Cole, R. H. Cole, J. Chem. Phys. 1941, 9, 341. 
$\chi^{\prime \prime}=\left(\chi_{S}-\chi_{T}\right) \tan \left(\frac{\pi \alpha}{2}\right)+\sqrt{\left[\left(\frac{\chi_{S}-\chi_{T}}{2}\right)^{2}\left\{\left[\tan \left(\frac{\pi \alpha}{2}\right)\right]^{2}+1\right\}-\left(\chi^{\prime}-\frac{\chi_{S}-\chi_{T}}{2}\right)^{2}\right]}$ equation 1

\section{AC susceptibility investigations for $\left[\operatorname{Er}(\mathrm{L})_{3}(\right.$ phen $\left.)\right] \cdot 0.5 \mathrm{H}_{2} \mathrm{O}, 4$ :}

Figure SI5. Compound 4:Temperature and frequency dependence of the in-phase $(\chi)$ and out-of-phase $\left(\chi^{\prime}\right)$ ac susceptibilities recorded at 1000 Oe dc field with a 3 Oe ac field with frequencies and temperatures ranging from 1 to $1500 \mathrm{~Hz}$ and 2 to $5.8 \mathrm{~K}$, respectively. The solid lines in $\chi_{\mathrm{M}}{ }^{\prime \prime}=\mathrm{f}(v)$ are the best-fits to the Debye model.
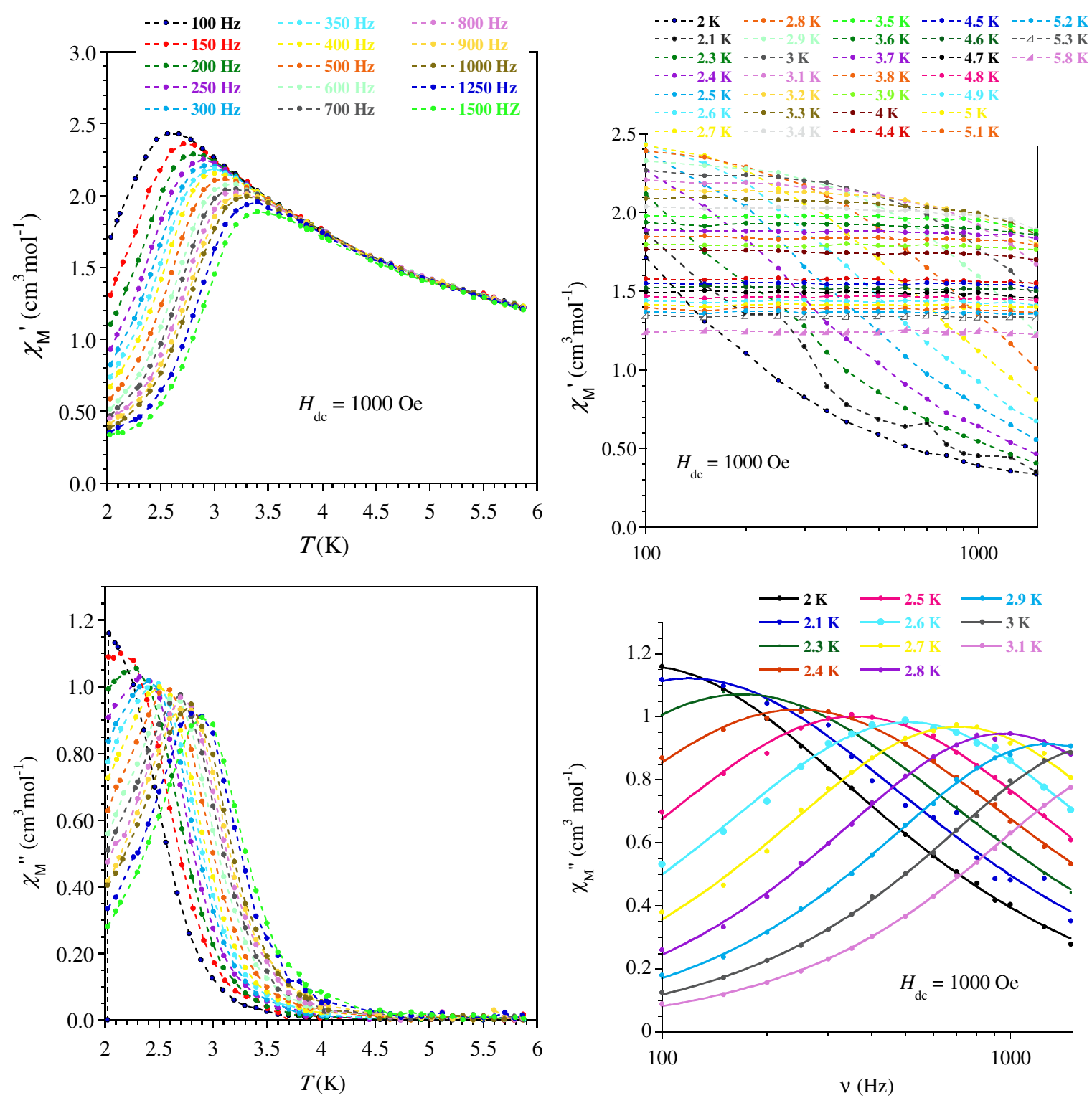
Figure SI6. Analysis of the relaxation time for 4 (left) with Raman and (right) with Arrhenius equations; best fits are depicted with red line and related parameters are given on the plots.
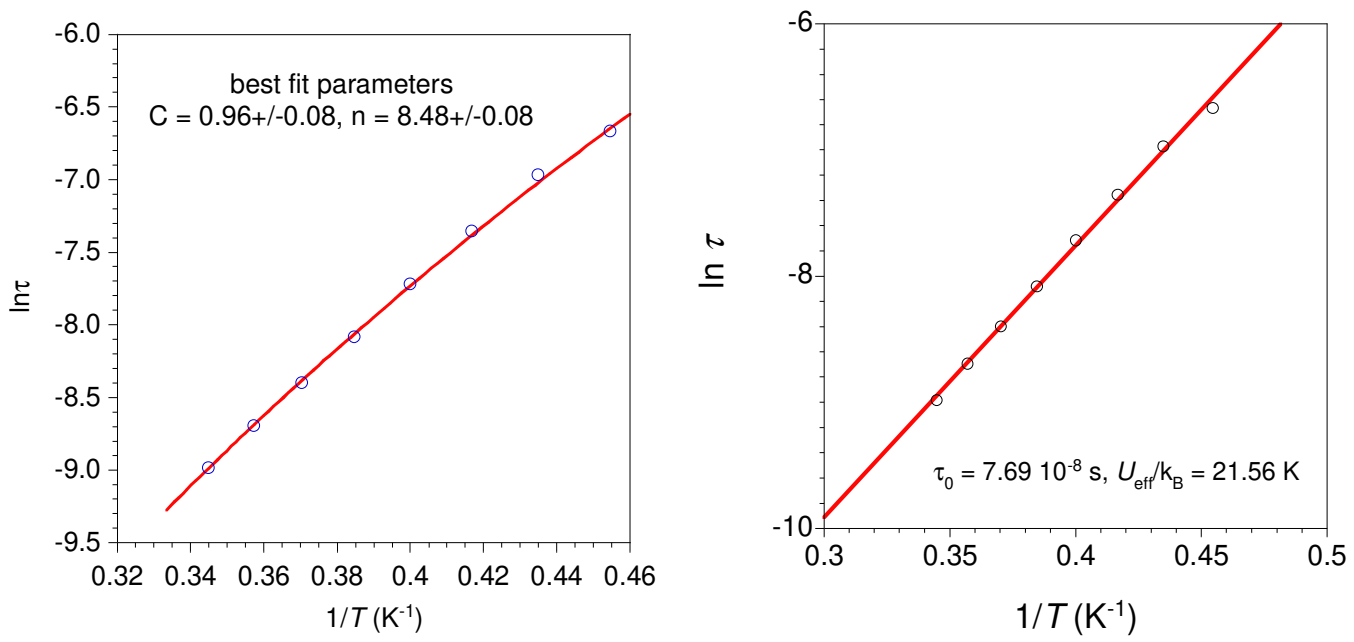
Figure SI7. Cole-Cole $\left(\chi_{\mathrm{M}}{ }^{\prime}{ }^{\prime}=\mathrm{f}\left(\chi_{\mathrm{M}}{ }^{\prime}\right)\right)$ plots for 4 between 2.1 and $3.2 \mathrm{~K}$ with the best fits to the generalized Debye model (equation 1) ${ }^{4}$; best fit parameters are gathered in the table.

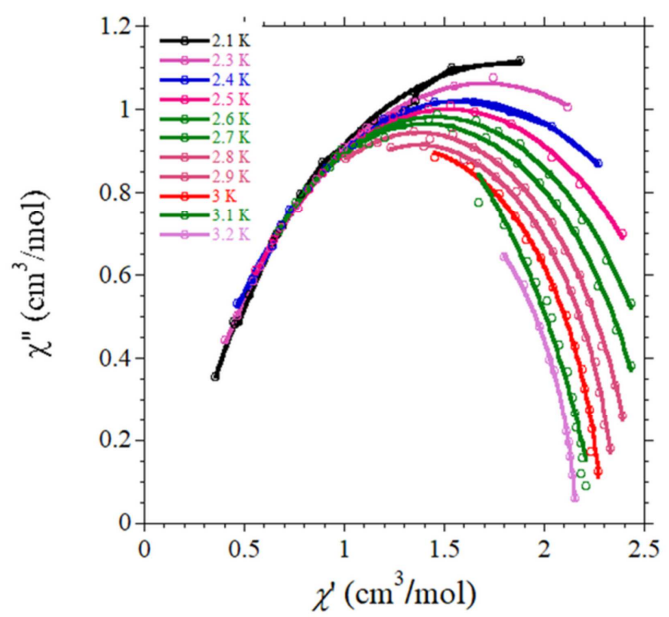

\begin{tabular}{ccccc}
\hline $\boldsymbol{T}(\mathbf{K})$ & $\chi_{\boldsymbol{\top}}\left(\mathbf{c m}^{\mathbf{3}} \mathbf{~ m o l}^{-1}\right)$ & $\chi_{\mathbf{S}}\left(\mathbf{c m}^{\mathbf{3}} \mathbf{~ m o l}^{-1}\right)$ & $\alpha$ & $\boldsymbol{R}^{\mathbf{2}}$ \\
\hline 2.1 & 3.4486 & 0.16332 & 0.24041 & 0.99919 \\
2.3 & 3.2354 & 0.15603 & 0.23185 & 0.99977 \\
2.4 & 3.0439 & 0.15152 & 0.21640 & 0.99884 \\
2.5 & 2.7933 & 0.22243 & 0.15663 & 0.99858 \\
2.6 & 2.6848 & 0.22849 & 0.14042 & 0.99988 \\
2.7 & 2.5647 & 0.23263 & 0.11640 & 0.99916 \\
2.8 & 2.4557 & 0.28786 & 0.086078 & 0.99946 \\
2.9 & 2.3461 & 0.43127 & 0.036630 & 0.99918 \\
3 & 2.2829 & 0.37339 & 0.036491 & 0.99948 \\
3.1 & 2.2152 & 0.36637 & 0.040299 & 0.99966 \\
3.2 & 2.1576 & 0.36193 & 0.050824 & 0.99952 \\
\hline
\end{tabular}

\footnotetext{
${ }^{4}$ K. S. Cole, R. H. Cole, J. Chem. Phys. 1941, 9, 341.
} 